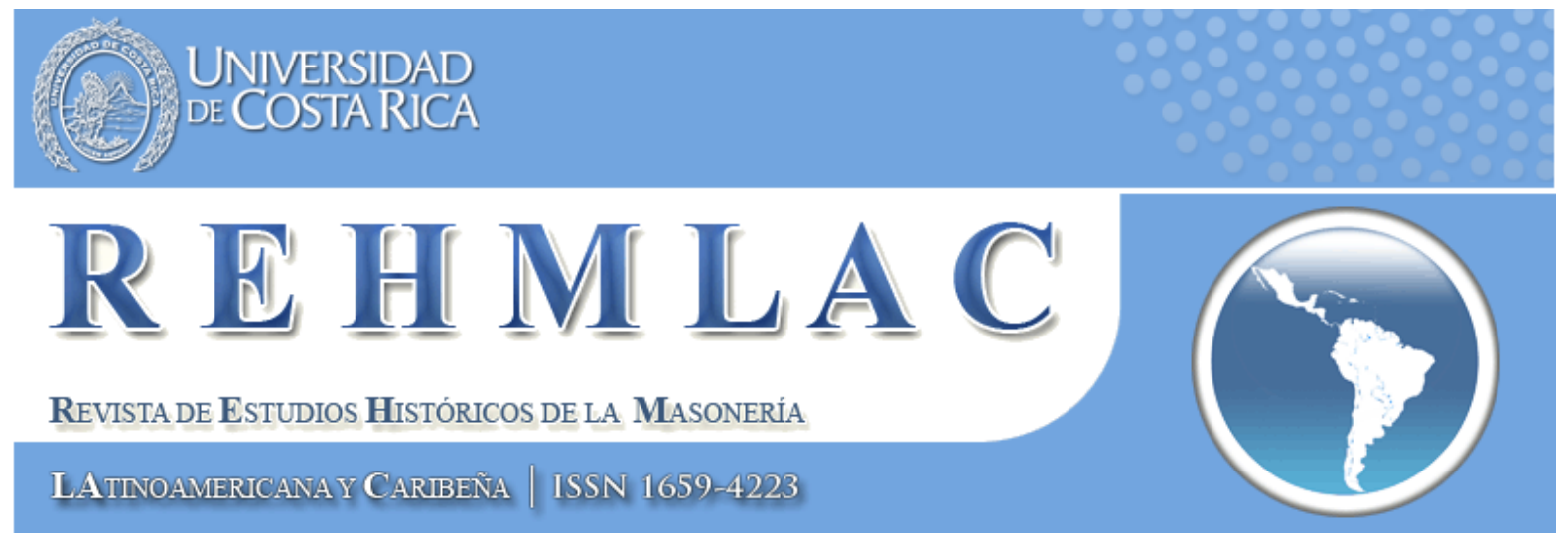

"La influencia de la masonería madrileña en la política de la Segunda República Española (1931-1939)"

\author{
Manuel Según-Alonso
}


(C) Manuel Según-Alonso y REHMLAC.

\section{Equipo REHMLAC}

Consejo Científico:

Miguel Guzmán-Stein (Universidad de Costa Rica, Costa Rica)

José Antonio Ferrer Benimeli (Universidad de Zaragoza, España)

Margaret Jacob (University of California Los Angeles, United States)

Eduardo Torres Cuevas (Universidad de La Habana, Cuba)

María Eugenia Vázquez Semadeni (Stanford University, United States)

Éric Saunier (Université du Havre, France)

Andreas Önnerfors (Lunds universitet, Sverige)

Samuel Sánchez Gálvez (Universidad Carlos Rafael Rodríguez de Cienfuegos, Cuba)

Roberto Valdés Valle (Universidad Centroamericana “José Simeón Cañas”, El Salvador)

Céline Sala (Université de Perpignan, France)

Dominique Soucy (Université de Franche-Comté, France)

Guillermo de los Reyes Heredia (University of Houston, United States)

Dévrig Mollès (Université de Strasbourg, France)

Felipe Santiago del Solar Guajardo (Universidad ARCIS, Santiago de Chile)

Carlos Francisco Martínez Moreno (Universidad Nacional Autónoma de México, México)

Michel Goulart da Silva (Universidade do Estado de Santa Catarina, Brasil)

Correctores de estilo:

Sylvia Hottinger (Centro de Estudios Históricos de la Masonería Española, España)

Kyle Jackson (University of California Los Angeles, United States)

Diseñador y administrador $W e b$ :

Luis Martín Valverde Alfaro (Universidad de Costa Rica, Costa Rica)

Editor:

Yván Pozuelo Andrés (IES Universidad Laboral de Gijón, España)

Correo electrónico: yvan@edu.xunta.es

Director:

Ricardo Martínez Esquivel (Universidad de Costa Rica, Costa Rica)

Correo electrónico: ricardo.martinezesquivel@ucr.ac.cr

Dirección Web: rehmlac.com/

Correo electrónico: info@rehmlac.com

Apartado postal: 243-2300 San José, Costa Rica 


\section{Citado en:}

Academia.edu

Aladin. WRLC. Libraries Catalog

AFEHC. Asociación para el Fomento de los Estudios Históricos en Centroamerica

Biblioteca de Georgetown

CRICCAL, Université Sorbonne Nouvelle Paris 3

CERGE EI. Portál elektronických časopisů. Univerzita Karlova v Praze

Departamento de Filosofía de la Universidad Centroamericana "José Simeón Cañas"

Dialnet, Universidad de la Rioja

Directorio y recolector de recursos digitales del Ministerio de Cultura de España

DOAJ. Directory of Open Access Journals

e-revist@s. Plataforma Open Access de Revistas Científicas Electrónicas

Freemasonry and Civil Society Program at UCLA

Fudan University Library Academic Resource Portal

Google académico

Institute for the Study of the Americas at University of London

Latindex (UNAM)

Latindex.ucr. Repositorio de revistas de la Universidad de Costa Rica

Library Catalogue of University of South Australia

Museo Virtual de la Historia de la Masonería de La UNED

Nuevo Mundo. Mundos Nuevos

REDIAL. Red Europea de Información y Documentación sobre America Latina

SciELO - Scientific Electronic Library Online

Sherpa/Romeo

SID. Sistema Integrado de Documentación. Universidad Nacional de Cuyo

Toronto Public Library

UBO. Revues en ligne. Université de Bretagne Occidentale

Universia. Biblioteca de Recursos

University of Saskatchewan Library

University of Wiscosin-Madison Libraries

Western Theological Seminary. Beardslee Library Journals 


\title{
"La influencia de la masonería madrileña en la política de la Segunda República Española (1931-1939)"
}

\author{
Manuel Según-Alonso \\ Doctorando en Historia del Arte y Territorio en la UNED, España. Título provisional de la tesis: "Masonería y \\ Política en Madrid, 1900-1939". \\ Correo electrónico: segunam@madrid.es
}

Fecha de recibido: 2 octubre 2014 - Fecha de aceptación: 8 noviembre 2014

\section{Palabras clave}

Madrid, anticlericalismo, dictadura, política, republicanismo, Grande Oriente Español, Gran Logia Española

Keywords

Madrid, Anticlericalism, dictatorship, politics, republicanism, Grand Orient of Spain, Grand Lodge of Spain

\begin{abstract}
Resumen
Las criticadas interconexiones entre masonería y política en Madrid (España) deben abordarse desde diferentes puntos de vista, puesto que nos encontramos ante una institución compleja, estructurada en varios niveles de acción: masones, logias y Obediencias. Además, a la masonería madrileña se le ha atribuido objetivos partidistas como la lucha contra el poder de la dictadura, el clero y la monarquía; y a favor de una sociedad laica y democrática; así como un fuerte compromiso social. Hemos intentado explicar, dentro del contexto madrileño, el vínculo entre masonería y política (republicanismo) que hace que se cree un grupo ideológico de presión dentro de la masonería madrileña en la República Española (1931-1939).
\end{abstract}

\begin{abstract}
The criticised interconnections between freemasonry and politics in Madrid (Spain) should be approached from different points of view because we are dealing with a complex institution made of several entities: freemasons, lodges and Grand Lodges. Additionally, the Masonry of Madrid has been linked with political objectives such as to fight against the power of the dictatorship, the clergy, and the monarchy; and being in favour of a laic and democratic society; as well as a strong social commitment. We have tried to explain, within the context of Madrid, the link between masonry and politics (republicanism), which helped to create an influential ideological group within the Masonry of Madrid in the Spanish Republic (1931-1939).
\end{abstract}

\section{Introducción}

La masonería es un conjunto de organizaciones (obediencias ${ }^{1}$ y $\operatorname{logias}^{2}$ ) de carácter iniciático que han influido de una manera u otra, en la historia de Occidente, y cuyo fin, es el perfeccionamiento moral de sus miembros, teniendo prohibido hablar de religión y de política. Podríamos decir que la masonería quiso unir a hombres libres que "respetaban la moral natural y querían conocerse y trabajar juntos a pesar de la diversidad de sus opiniones religiosas y de su afiliación a confesiones o partidos más o menos opuestos" ${ }^{3}$.

Nosotros nos vamos a centrar en la masonería madrileña en la época de la Segunda República. Época, en la que existían dos principales Obediencias: Grande Oriente Español

\footnotetext{
${ }^{1}$ Dícese de un conjunto de logias que tienen las mismas constituciones o reglas.

2 Asociación o lugar donde se reúnen los masones, también se conoce como "taller" o "templo".

3 María Teresa Roldán Rabadán, "Cuestiones políticas y sociales tratadas por algunas logias madrileñas", en: Symposium de Metodología Aplicada a la Historia de la Masonería Española, coord. José Antonio Ferrer Benimeli (Córdoba: CEHME, 1987), Tomo I, 25-26.
} 
$(\mathrm{GOE})^{4}$, fundada en 1889; y la Gran Logia Española $(\mathrm{GLE})^{5}$, fundada en 1920. Ambas pertenecientes a la masonería que podríamos denominar latina, que como sabemos, fue la más comprometida con la lucha política ${ }^{6}$.

Por otro lado, advertimos que la relación entre masonería y política puede afrontarse desde distintos ángulos. De un lado, analizando cómo y cuándo las logias madrileñas y las obediencias han intervenido en el terreno político, es decir, en partidos, participando en el poder público o formulando leyes, y además lo han hecho en cuanto tales; de otro, viendo como estas organizaciones masónicas adquirieron responsabilidades políticas, lo que nos lleva a entender la importancia del masón dentro de la masonería, y los contrastes que existen entre ellos; por último, se puede investigar la biografía de los masones y su relevancia públicas; y distinguir, aunque sea complicado, cuales de sus acciones fueron hechas como hombre político o como masón.

Partiremos de la hipótesis de que la masonería es una sociedad iniciática tradicional dedicada al perfeccionamiento moral de sus miembros y que no es una religión, ni una secta, ni una asociación política, pero que si tuvo una influencia en el periodo estudiado, aunque no tanto por los individuos como masones como por los masones como políticos. Nos centraremos en el caso de la ciudad de Madrid y analizaremos la influencia que tuvieron los masones madrileños $^{7}$ en las redes políticas del periodo republicano. Viendo si la masonería oficial, y especialmente la madrileña, se involucró en el devenir político por mucho que su lenguaje oficial dijera lo contrario. En definitiva, las cuestiones a estudio son: qué influencia tuvieron las logias madrileñas y la Gran Logia Regional Centro (GLRC) en la vida política madrileña, cómo actuaron tras el inicio de la guerra y qué represión sufrieron tras el triunfo de los sublevados.

\section{El inicio de la República}

La llegada de la República fue percibida por las logias madrileñas, con esperanza. Para muchos suponía que había que volver al terreno iniciático y dejar la beligerancia que había mostrado frente a la dictadura. Pero no había pasado ni un mes, cuando se produjeron los sucesos conocidos como "la Quema de Conventos"; motín popular madrileño que se produjo entre los días 10 y 11 mayo de 1931, extendiéndose a otras ciudades y del que fueron otra vez

\footnotetext{
${ }^{4}$ Un esquema de la Organización del GOE en la II República se puede ver en Yván Pozuelo Andrés, $L a$ masonería en Asturias (1931-1939) (Universidad de Oviedo, 2012), 281.

${ }^{5}$ La Gran Logia Simbólica Catalano-balear cambió el nombre a Gran Logia Española en 1920, en un intento de extender su campo de acción a toda España. La GLE, en 1931, se propuso trasladar su sede a Madrid que no hará efectiva hasta 1934.

${ }^{6}$ Se acepta mayoritariamente que existe dos masonerías, la anglosajona, también denominada dogmática o regular; y la latina o continental, denominada, adogmática o irregular. La segunda, a diferencia de la primera, acepta la iniciación de mujeres y deja a la conciencia individual la creencia en un Ser Supremo o "Gran Arquitecto del Universo" (GADU). Las dos obediencias españolas principales iniciaron a mujeres y pertenecieron a la Asociación Masónica Internacional (AMI), vinculada al Gran Oriente de Francia (GOdF) y por tanto, a la masonería latina, además en el caso de la GLE no se invocaba al GADU. En el caso del GOE, se trató el tema, si hacemos caso a Rafael Gerona Martínez, en la declaración que prestó en el juicio sumarísimo que se siguió contra él. Archivo Histórico Militar (AHM), fondo Madrid, Sumario 55022 legajo 3833, 108.

${ }^{7}$ Entenderemos por masones madrileños, los pertenecientes a logias de Madrid.
} 
acusados, entre otros, los masones aunque como señala Alcalá Zamora: "ni siquiera facilitaron a la trama del crimen el aprovechamiento individual, nunca plan colectivo, del secreto y de la red de afiliado" 8 .

Desde varios medios periodísticos, en el momento de producirse el motín, se pedía la expulsión de los jesuitas, enemigos declarados de los masones. El Crisol, en primera página, y en mayúsculas, lo pide como una de las primeras medidas para restaurar el orden: "creemos conocer suficientemente al pueblo para asegurar que así se contribuiría poderosamente a un inmediato apaciguamiento de la cólera popular" ". Varios ministros masones de logias madrileñas como, Fernando de los Ríos, Marcelino Domingo, Albornoz y Azaña ${ }^{10}$, eran partidarios también de expulsar a los jesuitas. Tema que se trató en el consejo de Ministros y que Azaña defendió con el argumento de que era preferible hacerlo ahora que tras nuevos asaltos $^{11}$. Posición que la logia Mare Nostrum reflejó en una carta enviada el 19 de mayo a los masones que ocupaban altos cargos ${ }^{12}$. Tres meses más tarde, Azaña todavía se lamentaba de no haberlos expulsado en los días propicios de mayo ${ }^{13}$.

Del 23 al 25 de mayo de 1931, se celebró la Gran Asamblea de la GLE, en la que se adopta una "Declaración de Principios" que fue enviada el 20 de julio a ministros, diputados y altos cargos del régimen ${ }^{14}$; y en la que se pedía la incorporación a las leyes y al proyecto constitucional, sus principios ${ }^{15}$. Largo Caballero, Martínez Barrio, Fernando de los Ríos y Azaña, respondieron al "Gran Maestre" para cumplir sus peticiones ${ }^{17}$.

Pese a todo, 1931 fue un año en que las logias madrileñas tuvieron muy poca actividad, siendo denominado por González Castroverde ${ }^{18}$, "año de pasividad casi absoluta". Paradójicamente, "levantan columnas"19, un importante número de logias como, la de perfección Concordia ${ }^{20}$, y las simbólicas, República Portuguesa y Génesis ${ }^{21}$ del GOE; y

\footnotetext{
${ }^{8}$ Niceto Alcalá-Zamora, Memorias (Barcelona: Planeta, 1998), 218.

${ }^{9}$ Crisol, 12 de mayo de 1931.

${ }^{10}$ Azaña no era masón en ese momento, pero se iniciará en una logia madrileña en 1932.

${ }^{11}$ Manuel Azaña, Obras Completas. Tomo IV (México: Oasis, 1966), 51.

${ }^{12}$ Centro Documental de la Memoria Histórica, de Salamanca (en adelante CDMH), sección Masonería, Legajo 108A/21.

${ }^{13}$ Víctor Manuel Arbeloa, La Semana Trágica de la Iglesia en España: 8-14 de Octubre de 1931 (Madrid: Encuentro, 2006), 19.

${ }^{14}$ Arbeloa, La Semana Trágica de la Iglesia en España, 62.

${ }^{15}$ Declaración de principios, adoptados por la GLE en la Asamblea celebrada en Madrid los días 23, 24 y 25 de mayo de 1931, en: Arbeloa, La Semana Trágica de la Iglesia en España, 62.

16 "Gran Maestre", máxima autoridad de una obediencia.

${ }^{17}$ Ferrari Billoch. La Masonería al desnudo. Las Logias Desenmascaradas. (Madrid: Bergua, 1936), 243.

${ }^{18}$ Simbólico Agrófilo. Miembro de la logia Fuerza Numancia e iniciado el 14 de mayo de 1914. Socialista. Gran Maestre Adjunto en 1935.

19 "Levantad Columnas": inauguración de una logia.

${ }^{20}$ En la ceremonia de instalación de la logia Concordia en abril de 1931, el Venerable Maestro, José Marchesi, simbólico Justicia, afirma: "Es preciso que la Orden masónica se aliste para actuar en forma que esa influencia que en la vida pública nos atribuyen [...], sea realmente un hecho, un hecho real y tanguible". $B O G O E, 10$ de mayo de 1931, 8-11.

${ }^{21}$ Olivia Moviola, "La geopolítica de la masonería en Madrid, 1910-1936", en: La masonería española en el 2000. Una revisión histórica, coord. Ferrer Benimeli (Zaragoza: Gobierno de Aragón, 2001), Tomo I, 509-510.
} 
Primero de Mayo $^{22}$ de la GLE; además se afiliaron tres logias madrileñas a la GLE: Mantua, Life y Solidaridad $^{23}$. En 1932, Unión, pasa a depender de la GLE y en 1933, se instalan la logia Perfección no 21 y las logias Augusto Barcia (GOE), Isidoro Maiquez, Hiram y Conde de Aranda (GLE). En 1934, la logia Charitas (GLE) ${ }^{24}$. También levantan columnas y las logias de adopción ${ }^{25}$, Amor, (1931), dependiente de Mantua ${ }^{26}$; y "Reivindicación", patrocinada por "Condorcet" (GOE) ${ }^{27}$. En setiembre de 1931, se regularizaron las logias Dantón ${ }^{28}$ e Ibérica, que habían sido suspendidas desde las disensiones en la $\operatorname{GLRC}^{29}$ y se reabrió la Gran Logia Regional Centro (GLRC) ${ }^{30}$.

Debemos reseñar que hubo grandes diferencias entre las logias madrileñas en el tema político. Algunas como la Condorcet ${ }^{31}$, de carácter intelectual, se mantuvieron y defendieron el apoliticismo. En el lado opuesto, aparecen logias como Nomos, Unión, Dantón, Mare Nostrum, Luis Simarro, República Portuguesa, Ibérica, Perfección o Primero de Mayo. En estos años los cuadros lógicos mantuvieron el carácter pequeño burgués, aunque se iniciaron un mayor número de "eminencias" 32 .

\footnotetext{
${ }^{22}$ En el discurso de instalación de la logia Primero de Mayo se señala: "la significación que la inmensa mayoría de los hermanos del taller tenemos en la vida profana ha podido hacer creer a algunos, hacer temer a otros que nuestra logia fuera una logia política [...]. No somos una logia política, una logia masónica no puede ser una logia política. Todos los hermanos del taller, menos dos, somos socialistas y socialistas militantes. En el medio socialista hemos reclutado [...] nuestros aprendices, sin cerrar nunca nuestras puertas a cualquier hombre libre, honrado y de buenas costumbres. Hemos dado a nuestra logia el nombre de Primero de Mayo, símbolo del Trabajo. Pretendemos orientar nuestros trabajos masónicos hacia el estudio de los problemas sociales, pretendemos impregnar nuestras especulaciones intelectuales y morales de la rudeza, de la servidumbre, de la grandeza y de la miseria del trabajo que es la forma sensible de nuestro ideal. Fundamos la libertad en la independencia económica, la igualdad en la supresión de las clases, acudiendo, cuando sea preciso a la lucha contra las clases sociales que se oponen a la igualdad. Y proclamamos que no puede haber fraternidad mientras haya por el mundo explotadores y explotados, [...] Que no se asuste nadie si exigimos el sistema filosófico del materialismo histórico de Marx. [...]”. CDMH, sección Masonería, legajo 73A/3,

${ }^{23}$ BOGLE, septiembre de $1931,8-9$.

${ }^{24}$ Olivia Salmón Moviola, "La geopolítica de la masonería en Madrid, 1910-1936”, en: La masonería española en el 2000, Tomo I, 510.

25 "logia de adopción": logia femenina que dependía de una logia masculina.

${ }^{26}$ Boletín Secreto de la GLE, $\mathrm{n}^{\circ}$ 2, 10 en Natividad Ortiz Albear, Las mujeres en la Masonería (Málaga: Atenea. 2005), 123.

${ }^{27}$ Ortiz Albear, Las mujeres en la Masonería, 119-126.

${ }^{28}$ Hay pocos datos de la logia Dantón en el CDMH, un par de cuadros lógicos y una carta. CDMH, sección Masonería, 733A/22.

${ }^{29}$ Acta del Gran Consejo Federal Simbólico, de 14 de septiembre de 1931, 13.

${ }^{30}$ Luís P. Martín, Los arquitectos de la República: Los masones y la politica en España, 1900-1936 (Madrid: Marcial Pons, 2007), 138.

${ }^{31}$ En ella encontramos a figuras como José Gómez de la Serna, Luis Massip del Rey y al antiguo Gran Maestre de la Orden, José María Rodríguez. Simbólico Argentino. Nació en Cabranes (Asturias) el 9 de marzo de 1872. A los 10 años marchó a la República Argentina y regresó a España en 1905, fijando su residencia en Gijón, donde fue concejal y teniente de Alcalde por el partido Republicano. Se inició en el Triángulo Amese de Gijón en 1911, exaltado a compañero por delegación de la Respetable Logia Ibérica y fundador y Venerable de la logia Jovellanos. En 1916 era grado 33. Gran Maestre del GOE hasta el traslado de su sede a Sevilla y desde enero de 1934 hasta su muerte el 11 de diciembre de 1934, Gran Soberano Comendador del Supremo Consejo de Grado 33. Boletín Oficial del Supremo Consejo de Grado 33 para España y sus Dependencias, no. 410. Año XLII. (diciembre de 1934) y no. 407. Año XLII. (marzo de 1934).

${ }^{32}$ Figuran en los cuadros lógicos durante la etapa republicana hombres tan significados en la Cámara como Eduardo Ortega y Gasset, Bello Trompeta, Cámara Cendoya, Franco Bahamonde, Gómariz de la Torre, Guerra del Rio, Mirasol Ruiz, Moreno Mateo, Ruiz del Toro; es decir, algunos de los “jabalíes” del Parlamento. A estos
} 


\section{Los masones madrileños en política}

La República supone el momento histórico en el que más masones madrileños fueron llamados a ocupar cargos públicos, lo que hará que dejen de trabajar en logia elementos muy significativos $^{33}$. Pero no solo ocuparan puestos en la circunscripción madrileña sino que lo harán en otras regiones lo que provocara fricciones con otras grandes logias regionales. A esto, se une, que entre los madrileños, hay muchos militantes de partidos republicanos de nuevo cuño, mientras que los de otras regiones, como la andaluza, pertenecen mayoritariamente, al republicanismo radical ${ }^{34}$.

La doble pertenencia masonería y partido, será complicada debido a que los enfrentamientos entre los grupos republicanos serán continuos y tendrá eco en las logias madrileñas. Muchas de las figuras políticas notables en los años anteriores, dejarán de serlo, y otras, tomaran notoriedad. Entre las primeras, tenemos a Graco Marsá, Torres Campañá y Martí Jara; entre las segundas, a Pedro Rico, José Giral, Royo Gómez, Luis Bello, Roberto Castrovido, Mirasol Ruiz, Castro Bonell, Pedro Vicente Gómez Sánchez de Acción Republicana. Del partido Radical Socialista, a Albornoz, Botella Asensi, Galarza, Eduardo Ortega y Gasset, Palomo Aguado, Pérez Madrigal, Artigas Arpón y José Salmerón. Los socialistas son Jiménez de Asúa, Fabra Rivas, Rodolfo Llopis, Martínez Gil, Álvarez Angulo, Hermenegildo Casas, Rodríguez de Vera, Juan Simeón Vidarte, de Francisco. De los federales Barriobero y Arauz Pallardo. Un miembro de la Esquerra, Ramón Franco Bahamonde. Y por último, por el partido Radical, podemos nombrar a Guerra del Río, Salazar Alonso o Torres Campañá. De logias madrileñas, eran varios ministros, Alejandro Lerroux ${ }^{35}$, Santiago Casares Quiroga ${ }^{36}$; Marcelino Domingo y Álvaro de Albornoz fundadores de la Dantón. En el segundo gobierno Provisional, entra José Giral, otro miembro de una logia madrileña ${ }^{37}$.

El amplio número de diputados masones, su prestigio y la preponderancia de masones de logias madrileñas, "alentaron las expectativas intervencionistas de las logias" en las Cortes, lo que llevó a gestionar la celebración de reuniones de diputados masones para tratar temas "de común conveniencia"38. La Gran Comisión de Asuntos Generales del Gran Consejo, compuesto entre otros, por Juan Sarracell, Gil Mariscal y Elías Palasí ${ }^{39}$, emiten un dictamen

talleres madrileños también pertenecían, algunos de sus dirigentes como Juan Manuel Iniesta, Aselo Plaza, Ceferino González, Roberto Ruiz o Ramón Cuesta. Gómez Molleda, La masonería en la crisis española, 228229, 309 y 404-406.

${ }^{33}$ Martín, Los arquitectos de la República, 139.

${ }^{34}$ Juan Avilés Farré, La Izquierda Burguesa y la tragedia de la II República (Madrid: Comunidad de Madrid, 2006), 110.

35 Se inicia en 1886, en la logia Verónica de Madrid, afiliándose en 1917 en la logia Adelante de Barcelona, hasta que en 1932, pasará a formar parte de la Unión, logia del GOE.

${ }^{36}$ Procedía de la logia Condorcet, después pasó a la Hispanoamericana para por último, encontrarle, ya fuera de Madrid, en la logia Suevia de A Coruña.

${ }^{37}$ José Giral Pereira, simbólico Noble. Se inició, el 5 de diciembre de 1926, en la Dantón, y exaltado al $2^{\circ}$ y $3^{\circ}$ grado en mayo de 1927.

38 Diego Martínez Barrio, a la Gran Logia Regional Nordeste, 17 de julio de 1931. Gómez Molleda, La masonería en la crisis española, 318-320.

${ }^{39}$ Juan Sarradell, simbólico Pino, abogado y Venerable de la logia La Unión. Félix Gil Mariscal, simbólico Lucrecio, abogado y miembro de la logia Concordia. Elías Palasí Cester, simbólico Henry George, empleado y miembro de la logia Luis Simarro. 
favorable al proyecto de reunión de diputados, el 6 de agosto de 1931 de conformidad al artículo 12 de la Constitución del GOE pero condicionado a que las reuniones debían ser tenidas, en las que no se podrían hacer iniciaciones, aumento de salarios o exaltaciones; además de los diputados masones, deberían asistir el Gran Comendador, el Gran Canciller y el Gran Orador del Supremo Consejo de Grado 33 y el Gran Maestre, el Gran Secretario y el Gran Orador de la Comisión Permanente del Consejo Federal Simbólico y los ex Grandes Maestres. Esta condición, pretende moderar la situación ante posibles partidismos puesto que las personalidades del Supremo Consejo de Grado 33, tienen una mentalidad abstencionista, lo mismo que los ex Grandes Maestres, José María Rodríguez y Demófilo de Buen ${ }^{40}$. Las reuniones tuvieron lugar como atestiguan las citaciones que dirige Pedro Rico López, Gran Maestre de la Gran Logia Regional Centro (GLRC) ${ }^{41}$. También tuvieron lugar banquetes masónicos que se ajustaban a lo establecido:

En los días en que se estaba discutiendo La Constitución, los diputados de las Cortes Constituyentes nos reunimos en un gran banquete masónico [...]. También asistieron ministros y altos cargos del Gobierno. Presidían el Gran Maestre del Gran Oriente Español. Martínez Barrio; el Gran Maestre de la Gran Logia Española, Portela Valladares y el Gran Comendador, Augusto Barcía ${ }^{42}$.

\section{La masonería madrileña y la cuestión religiosa}

La masonería madrileña considera que el Estado debía ser aconfesional, respetuoso con la libertad de conciencia y de culto. Y por ello, dirige acciones divulgadoras de denuncia del clericalismo y desarrollan campañas a favor del matrimonio civil, el divorcio, la secularización de los cementerios y la educación laica. La tolerancia, la solidaridad y el universalismo que defienden, es incompatible con la enseñanza en centros religiosos ${ }^{43}$. Según Juan Simeón Vidarte, en octubre de 1931:

Nosotros [los socialistas] éramos laicos y no teníamos problemas personales en relación con la Iglesia católica [...]. No existía la menor semejanza entre los hombres de nuestra minoría y los radicales o los radicales-socialistas [...]. Sin embargo, fueron ellos lo más anticlericales y los que crearon en la Cámara el subconsciente colectivo que oprimía nuestra libre deliberación ${ }^{44}$.

\footnotetext{
${ }^{40}$ Para conocer más de Demófilo de Buen, ver María del Carmen Fernández Albéndiz, "Demófilo de Buen (Madrid, 1890-México, 1946)", en: Revista de Francmasonería CM Cultura Masónica 14 (2013): 93-99.

${ }^{41}$ Este artículo decía "varios Talleres de esta misma localidad y de localidades diferentes dentro de la respectiva jurisdicción pueden reunirse para deliberar colectivamente, ya sean reuniones plenas o por delegaciones, sobre cuestiones de interés general masónico. La resoluciones tomadas en estas reuniones o delegaciones, no deben en ningún caso atentar contra lo estatuido en la presente Constitución y en las leyes masónicas. Para celebrar estas reuniones se dará cuenta a la logia Regional respectiva o al Gran Consejo del Grande Oriente Español....”. Constitución, Estatutos y Reglamentos Generales del Grande Oriente Español, Madrid, Imprenta Samarán . S. A., 13-14 y el Dictamen citado de 6 de agosto de 1931 en Gómez Molleda, La masonería en la crisis española, 320-321.

${ }^{42}$ Vidarte, Las Cortes Constituyentes, 136.

${ }^{43}$ Gómez Molleda, La masonería en la crisis española, 274.

${ }^{44}$ Vidarte, Las Cortes Constituyentes, 198.
} 
Y refiriéndose al partido Radical-Socialista afirma que "fue uno de los más anticlericales de España [...]. Ciertamente la casi totalidad de los miembros de dicho partido eran enemigos de la Iglesia Católica"45.

Se puede decir que unos de los temas que más atención planteó en las logias madrileñas fueron el clericalismo, la pena de muerte, la defensa del oprimido, la guerra ${ }^{46}$ y la escuela confesional. Este último tema fue tratado en la logia Condorcet, llegando a la conclusión que había que romper con la enseñanza tradicional, y la religiosa en la escuela pública $^{47}$. Eduardo Barriobero ${ }^{48}$, miembro de la Catoniana afirmará "este es el tema de toda mi vida. No hemos hecho más que defendernos de la Iglesia". Dos talleres que sobresalieron en propuestas educativas con connotaciones ideológicas y sociales, fueron la logia Mantua y la Concordia de la GLE.

\section{La constitución y la masonería madrileña ${ }^{49}$}

Un masón madrileño, Jiménez de Asúa ${ }^{50}$, presidente de la Comisión Parlamentaria que elaboró el proyecto de Constitución ${ }^{51}$, la presenta a la Cámara el 27 de agosto de $1931^{52}$. Y precisamente, la discusión de sus artículos, el $26^{53}$, dejó en evidencia que no existe unidad entre los diputados masones ${ }^{54}$. De hecho el tema religioso mostró, como diría Marcelino Domingo, que "la iglesia había tenido la fortuna de unir a los antirrepublicanos y a separar a los republicanos" $"$.

La prohibición de la enseñanza a las órdenes religiosas, se deben a Roberto Castrovido de la logia Ibérica y Luis Bello de la Dantón ${ }^{56}$. El 21 de noviembre de 1931, la GLRC traslada

\footnotetext{
${ }^{45}$ Vidarte, Las Cortes Constituyentes, 147.

${ }^{46}$ Como ejemplos de los temas tratados ver Boletín Oficial del Supremo Consejo de Grado 33 para España y sus Dependencias, $n^{\circ} 410$. Año XLII. Diciembre de 1934 p. 10-11 y no 401. AÑO XL. Septiembre de 1932 p. 9 y nº 413-414. Año XLIII. Septiembre-Diciembre de 1935 p. 12-14.

${ }^{47}$ Gómez Molleda, La masonería en la crisis española, 309-310.

${ }^{48}$ Había nacido en Torrecilla de Cameros en 1875. Republicano de izquierdas, formó parte del partido Federal y de la Unión Republicana y colaboró con periódicos de carácter nacional. Abogado. Diputado ya en 1914. Participó en la Sanjuanada, y por ésta y otras actividades de oposición estuvo varias veces encarcelado. En 1912, era maestro en la Catoniana $\mathrm{n}^{\circ} 2$ y en 1917. Grado 33. Autor del libro: La Francmasonería Sus apologistas y sus detractores (Madrid. Imprenta de Galo Sáenz, 1925). Su lectura fue recomendada a los afiliados en Circular número 814 del Gran Secretario del Consejo Federal Simbólico.

${ }^{49}$ Para una información más completa sobre la masonería y los debates políticos ver José Ignacio Cruz, "La masonería española y los debates políticos de la II República", en: Revista de Francmasonería CM Cultura Masónica 19 (2014): 29-50

${ }^{50}$ Simbólico Carraca. Nació en Madrid, el 19 de junio de 1889. Iniciado el 29 de abril de 1927. Miembro de la logia Dantón y de Primero de Mayo. Profesor universitario. Miembro del partido socialista. Se exilió en Buenos Aires donde murió el 16 de noviembre de 1970.

${ }^{51}$ En la comisión, podemos encontrar otros masones madrileños, como el socialista, Enrique de Francisco Giménez, de la logia Ibérica.

${ }^{52}$ Marcelino Domingo Sanjuán, La experiencia del poder (Madrid: Javier Morata, 1934), 327-328.

${ }^{53}$ También encontramos masones madrileños en los debates del artículo 26, como el radical, Guerra Rio o el radical-socialista, Marcelino Domingo.

${ }^{54}$ Gómez Molleda, La masonería en la crisis española, 313 y 325.

${ }^{55}$ Sanjuán, La experiencia del poder, 139.

${ }^{56}$ Gómez Molleda, La masonería en la crisis española, 379.
} 
a las otras logias regionales, una propuesta de la logia Hispanoamericana ${ }^{57}$ en la que se defendía la necesidad de "sugerir a los diputados masones la conveniencia de incluir un artículo adicional al proyecto de Constitución, en el cual se suspendan los derechos de personalidad jurídica de todas las asociaciones religiosas y de sus miembros, cualquiera que sean sus fines o fe religiosa" ${ }^{\text {58. }}$.

Acción Republicana presenta una enmienda, proponiendo que la Iglesia sea considerada corporación de derecho Público con un estatuto especial. Propuesta aprobada por varios diputados, miembros de logias madrileñas ${ }^{59}$ que se muestran pragmáticos, no queriendo un enfrentamiento con el catolicismo sino lograr una República laica, acorde con las postura oficial del GOE. Pero existía otro grupo de masones madrileños, menos partidario del entendimiento ${ }^{60}$, que defiende la disolución de las órdenes religiosas, nacionalización de sus bienes y equiparación de la iglesia Católica con las demás religiones. Propuesta defendida por Botella ${ }^{61}$.

\section{La caída de los radicales y el tríunfo de los críticos}

En Madrid, en 1932 se había consolidado un importante número de masones socialistas y radical-socialistas que no compartían los postulados del partido Radical, mayoritario en el GOE, y en el que militaba el propio Gran Maestre Nacional, Martínez

\footnotetext{
${ }^{57}$ Resulta complicado reconstruir la historia de esta logia debido a la escasa documentación que existe. En sus filas encontramos a Enrique Barea que sustituyó a Diego Martínez Barrio, en octubre de 1934, como Gran Maestre Nacional del GOE y fue secretario del alcalde de Madrid, el también masón de esta logia, Pedro Rico, socialista y diputado. Santiago Casares Quiroga, republicano de izquierda, varias veces ministro y el último Presidente del Consejo antes del comienzo de la guerra de España. Juan Botella Asensí, político radicalsocialista, desempeñó el cargo de Ministro de Justicia en los primeros gabinetes de Lerroux y Martínez Barrio. Gerardo Abad Conde, político galleguista y republicano radical, ministro de Marina en el cuarto gabinete Lerroux. Muley Abdel Hafid, Sultán de Marruecos. Fermín Galán Rodríguez, uno de los capitanes que encabezó la sublevación de Jaca. Segismundo Casado, general del ejército de Centro en la Guerra de España de 1936 encabezó el pronunciamiento contra el gobierno de Negrín en la zona dominada por el Frente Popular. Roberto Villa García, "La logia Hispanoamericana $\mathrm{n}^{\circ} 379$ de Madrid (1915-1935)", en: La masonería en Madrid y en España del siglo XVIII al XXI, coord. Ferrer Benimeli (Zaragoza: CEHME, 2004), Tomo I, 104-105.

${ }^{58}$ Circular de la Gran Logia Regional de Centro, 21 de noviembre de 1931 en Gómez Molleda, La masonería en la crisis española, 404.

${ }^{59}$ Honorato de Castro Bonnell, de la Condorcet; Giral Pereira, Bello Trompeta y Vergara Castrillón, de la Dantón; José Royo Gómez y Peñalba Alonso, de la Mare Nostrum.

${ }^{60}$ En este grupo encontramos a Guerra del Río, Marcelino Martín González de Arco y Rodolfo LLopis Ferrándiz de la Ibérica; Moreno Mateo, que en 1931, no era masón pero que se inició en 1932 en la Mare Nostrum; Eladio Fernández Egochega y Eduardo Martínez Torner de la Hispanoamericana; Ramón Beade Méndez de la Concordía; Juan Simeón Vidarte Franco; Jiménez Asúa; Ramón Franco Bahamonde; Eduardo Barriobero y a Eugenio Arauz Pallardó (federales); Carlos Espla Rizas, Roberto Castrovido Sanz (Acción Republicana). Entre los llamados "jabalíes", a Joaquín Pérez Madrigal, Jerónimo Gomáriz Latorre, y Eduardo Ortega y Gasset, Benito Artigas Arpón, José Ballester Gozalvo, Ángel Galarza Gago, José Moreno Galvache, Emilio Palomo Aguado, Francisco Saval Moris, Pedro Vargas Guerendiain, Antonio Villa Gutiérrez y Gregorio Villarias López; los más representativos de este grupo, fueron Juan Botella Asensi de la Hispanoamericana, Salvador Valera Aparicio de Primero de Mayo y Álvaro de Albornoz Liminiana de la Dantón. Gómez Molleda, La masonería en la crisis española, 340-357.

${ }^{61}$ Diario de Sesiones, 9 de septiembre de 1931, 827.
} 
Barrio. Este grupo, los "críticos" $"$, con la excusa de defender los principios de la Orden y de reconstruir la solidaridad masónica, quiso controlar a los cargos públicos, y especialmente a los diputados. Para ello, pretendía que dejaran sus puestos en el alto Organismo de la Obediencia, y así, neutralizar la influencia de los radicales ${ }^{63}$. El iniciador fue Aselo Plaza apoyado por el Gran Maestre de la GLRC, Juan Manuel Iniesta y del Gran Secretario Ceferino González Castroverde y otros miembros secundarios del Gran Consejo ${ }^{64}$.

Los radicales habían emprendido una campaña de derribo contra Azaña, acusándole de haber establecido "su dictadura"65. Al mismo tiempo que los conflictos internos de las logias madrileñas llevaron a una "verdadera rivalidad partidista". Lo que explica, en nuestra opinión, lo sucedido en la GLRC y el empeño de algunos miembros de las logias madrileñas, de controlar el Gran Consejo Federal Simbólico.

En ese periodo, se desarrollan dos asambleas, la primera, extraordinaria en febrero; y la segunda, ordinaria, en octubre-noviembre del $1932^{66}$. En la asamblea del 20 al 22 febrero de 1932, se aprobó, la obligación por escrito de todos los masones activos, o en sueños de ratificar el juramento masónico. Medida que pretende que la autoridad de la Orden estuviera por encima del partido en que militaban los cargos públicos y especialmente los diputados masones". La asamblea fue un éxito para los críticos y un varapalo para la Logia Regional del Mediodía, feudo radical pero, a su vez, quedó visible, la contradicción interna dentro de la GLRC, debido al antagonismo entre las logias de inspiración radical-socialistas y las de inspiración radical. La postura de Iniesta, miembro de los críticos, y que acababa de sustituir a Pedro Rico, en la Gran Maestría de la GLRC, contrastó con la de los dos miembros elegidos para representar a las logias madrileñas, Joaquín Dicenta y Mariano Benlliuve Tuero; ambos de la logia Unión, y obligados a defender el dictamen elaborado en la Asamblea Regional Centro. Dictamen que se oponía a cualquier enmienda que "atentase la intangibilidad de la Constitución de la Obediencia y que matizaba la propuesta relativa a la "ratificación de las promesas" haciendo hincapié en que los hermanos con cargo público "deberían dar testimonio de tolerancia poniendo siempre la fraternidad masónica por encima de todas las diferencias que pudieran separarles en las luchas políticas" ${ }^{\text {67. }}$.

\footnotetext{
${ }^{62}$ Las figuras claves de los críticos serán Aselo Plaza, pertenecía al Capítulo Esperanza en 1934 con grado 9 en Boletín Oficial del Supremo Consejo de Grado 33 para España y sus Dependencias, no. 410. Año XLII. (diciembre de 1934); Juan Manuel Iniesta Sancha, simbólico Alonso Quijano, fue Gran Maestre Regional Centro, vocal del Gran Consejo y miembro de la Nomos; y Ceferino González Castroverde, simbólico Agrófilo, miembro de Fuerza Numancia.

${ }^{63}$ El grupo "crítico" estaba influenciado por el GOdF, a través del visitador Félicien Court y por los frecuentes viajes de delegados madrileños a Francia a actos de confraternización. Gómez Molleda, La masonería en la crisis española, 40.

${ }^{64}$ Como Roberto Ruiz, de la Nomos; Vicente Costales, de la Hispanoamericana; Francisco Mata, de la Matritense y Félix Gil Mariscal, de la Concordia.

${ }^{65}$ Es importante remitirse al discurso de Lerroux de la plaza de toros de Madrid, de 21 de febrero de 1932 y el discurso de Manuel Azaña y las réplicas y contrarréplicas de Diego Martínez Barrio el 1 de marzo en las Cortes.

${ }^{66}$ Gómez Molleda, La masonería en la crisis española, 397.

${ }^{67}$ Dictamen de la Regional Centro, 18 de febrero de 1932 en Gómez Molleda, La masonería en la crisis española, 411-423.
} 
Al mismo tiempo, la masonería madrileña tuvo que enfrentarse a un nuevo hándicap, el enfrentamiento de masones políticos en las propias logias, lo que provocó la intervención del GOE:

Todo control, asistencia y colaboración ha de llevarse a cabo de modo que suponga un absoluto respeto a las ideas políticas de los hermanos; sin la más mínima tendencia y mira partidista, sino únicamente en defensa de los elevados principios de nuestra augusta $\operatorname{Orden}^{68}$.

Además, tuvo que aglutinar la sociabilidad de los masones en logia y en el parlamento, provocando no pocos conflictos que incidieron en el desarrollo masónico madrileño. En definitiva, se produce, dentro de las logias, tensiones entre los que apuestan por una "masonería neutra" y los que lo hacen por una "militante". Para unos, se había abandonado el verdadero trabajo masónico; para otros, era el momento de llevar a la sociedad los principios y valores en los que creían ${ }^{69}$.

El auge de las logias madrileñas y de su Gran Maestre, Iniesta, posibilitó que en los meses siguientes, se emprendieran varias peticiones a los cargos legislativos masones. Es el caso de la petición que se lanzó el 20 de marzo de 1932, desde la GLRC, apoyando la moción que habían presentado dos diputados masones perteneciente a logias madrileñas, Botella y Gomáriz $^{70}$, a todos los talleres de su jurisdicción y al Gran Consejo Federal Simbólico, solicitando que se dirijan a los hermanos diputados para que vean "el modo de suprimir o aminorar el presupuesto del culto y clero, en beneficio de la instrucción Pública",71.

A primeros de abril de 1932, la GLRC pretende que se haga efectiva "la ratificación de promesas a la Orden", puesto que la Comisión Permanente, había designado a la GLRC para recibirlas, pero éstas, se iban demorando. Ese mismo mes de abril, el día 13, un grupo de 30 de masones madrileños salieron hacia Huesca en una expedición, organizada por la logia Hispano-Americana, a la que había pertenecido Fermín Galán, para hacerle un homenaje ${ }^{72}$.

En la Asamblea semestral de la GLRC, Iniesta organiza el ataque definitivo al Gran Consejo Federal Simbólico del GOE, con la excusa de la falta de asistencia de los miembros políticos al mismo, la mayoría del partido radical, a los que acusa de total inoperancia (no había abordado el tema de la reforma estatutaria y no habían obligado a ratificar el juramento aprobado en la Asamblea Extraordinaria de febrero de 1932) ${ }^{73}$.

La respuesta del Consejo a la desautorización de la GLRC, fue convocar inmediatamente la Asamblea General Ordinaria en octubre de 1932, en la que presenta su dimisión la Comisión Permanente del Gran Consejo Federal Simbólico. En esta Asamblea, se produce la renovación casi total de los consejeros y la dimisión del Gran Maestre, ganando la tesis de la no compatibilidad de los cargos masónicos con los cargos públicos profanos. Se

\footnotetext{
${ }^{68} \mathrm{CDMH}$, Sección Masonería, legajo 602A.

${ }^{69}$ Martín, Los arquitectos de la República, 88-89.

${ }^{70}$ Diario de Sesiones, 10 de marzo de 1932.

${ }^{71}$ Gómez Molleda, La masonería en la crisis española, 443-444.

72 Boletín Oficial del Supremo Consejo de Grado 33 para España y sus Dependencias, no. 408. Año XLII. (Junio de 1934), 3-4.

${ }^{73}$ Gómez Molleda, La masonería en la crisis española, 444-445.
} 
acepta las dimisiones del Gran Maestre, pero se le pide que siga en su cargo hasta las nuevas elecciones. El poder del Gran Consejo pasó a manos de los críticos madrileños ${ }^{74}$. Podemos ver, como mientras que en los documentos oficiales, y desde la dirección del GOE se saca de los puestos de responsabilidad a los masones políticos; por otra, se invita a las logias, a la creación de redes de "ideario republicano laico". Se hace evidente el doble lenguaje de la $\mathrm{GLRC}^{75}$.

\section{La iniciación masónica de Azaña ${ }^{76}$ y la contraofensiva de Lerroux}

Estamos de acuerdo con Gómez Molleda y Avilés Farré que defienden la tesis de que la iniciación de Azaña fue una operación política ${ }^{77}$, que sorprendió a muchos, incluso los más cercanos a D. Manuel, como Giral, Mateo Hernández o de los Ríos ${ }^{78}$. Es sorprende lo que dice, el propio Azaña: "En la ceremonia [...], enorme concurrencia [...]. No me importó nada aquello y durante los preliminares estuve tentado de marcharme" ${ }^{\text {"79 }}$. Por otro lado, parece apoyar la tesis de la operación política que eligiera la logia histórica y de tendencia izquierdista, Matritense, donde además era Venerable Aselo Plaza, Gran Secretario del Consejo y hombre clave del sector crítico. El Gran Maestre no acudió, lo que no pasó desapercibido a Manuel Azaña: "Martínez Barrio, Gran Gerifalte de la Casa, no asistió, quizás por los resquemores de estos días" 80 .

Para Vidarte y Fernando de los Ríos es claro que la entrada de Azaña en la Orden estaba relacionada con la oposición de los radicales al Gobierno ${ }^{81}$. Rafael Gerona Martínez ${ }^{82}$ afirma: "al rumorearse que Azaña proyectaba ingresar en la Masonería para hacerse dueño de mucho poder de ésta, los radicales decidieron ingresar en masa en la organización para evitar la jugada de Azaña" ${ }^{83}$. Por su parte, el sector crítico de la Obediencia vio ventajas en la iniciación de Azaña pues tenía un personaje de peso en sus filas que podía aunar los descontentos de las logias ante los postulados de los radicales y eclipsar el liderazgo del Gran

\footnotetext{
${ }^{74}$ Entre ellos, nombraremos, al nuevo Gran Secretario, Ceferino González Castroverde, bien relacionado con Aselo Plaza e Iniesta, dentro de la logia Nomos. De la Nomos, también eran Roberto Ruiz García (simbólico León) y Pérez Urria (Simbólico Miguel Servet). De la Hispanoamericana, Vicente Costales; de la Mare Nostrum, Eugenio Arauz Pallardo; de la Luís Simarro, Ramón Cuesta Arranz de la Torre; y de la Matritense, Francisco Mata y del Pozo.

${ }^{75}$ Martín, Los arquitectos de la República, 143.

${ }^{76} \mathrm{La}$ iniciación tuvo lugar el 2 de marzo de 1932. Simbólico Plutarco. En ese momento D. Manuel era presidente del Gobierno y ministro de la Guerra.

${ }^{77}$ Gómez Molleda, La masonería en la crisis española, 182-185.

${ }^{78}$ Vidarte, Las Cortes Constituyentes, 368.

${ }^{79}$ Azaña, Memorias políticas y de guerra (Barcelona: Grijalbo, 1996), 342.

${ }^{80}$ Se refería al enfrentamiento que tuvieron el 1 de marzo de 1932 en las Cortes. Azaña, Memorias políticas y de guerra, 342 .

${ }^{81}$ Vidarte, Las Cortes Constituyentes, 367-368

${ }^{82}$ Simbólico Dantón y Paz y Amor. Nació el 9 de febrero de 1879. Militar, periodista y publicista. Grado $3^{\circ}$. Iniciado en la logia Life en 1925. Miembro de las logias Life, Hiram 95, Unión 9, Unión 88, Conde de Aranda 97. Consejero de la GLE. Secretario del Consulado del Perú en Madrid en 1936-1937 desde donde protegió y salvo la vida a muchas personas simpatizantes con los sublevados. En 1937 se paso a la zona sublevada. Condenado a 20 años de prisión menor. CDMH, sección Masonería, legajo 115B/3, AHM, fondo Madrid, Sumario 55022 legajo 3833.

${ }^{83}$ AHM, fondo Madrid, Sumario 55022 legajo 3833.
} 
Maestre. En nuestra opinión, Azaña, pretendió con su iniciación, ganarse al movimiento de izquierdas que había tomado el control de la GLRC y que intentaba hacerlo del Gran Consejo de la Obediencia.

La contraofensiva, se produjo, pocos días después, también en marzo, cuando Lerroux abandona la logia Adelante de Barcelona perteneciente a la GLE, y se afilia a la logia Unión del GOE, logia "política" cercana a los radicales. En esta logia, estaban varios incondicionales de Lerroux como el venerable, Juan Sarradell que además era vocal del Gran Consejo Federal Simbólico ${ }^{84}$.

Enterado del plan, el Gran Maestre de la GLRC, Juan Manuel Iniesta, no tardó en tomar medidas para acabar con el grupo de simpatizantes de D. Alejandro y por ende, con la Unión. El 23 de noviembre de 1932, tras la Asamblea Ordinaria del Consejo, destituyó al venerable de la Unión, Juan Sarradell, y sancionó a varios de sus miembros ${ }^{85}$. La excusa, "las deficiencias observadas en la apertura de los libros de la logia, concesión de afiliaciones sin los requisitos exigidos [...], e irregularidades en el funcionamiento de la tesorería". Antes de que disolvieran la logia, sus miembros decidieron darse "plancha de quite", y con ello, poder afiliarse a otra logia. Muchos de los miembros, se afiliaron a la GLE, y fundaron la Unión $n^{\circ}$ 88, que tuvo su instalación definitiva en agosto de $1932^{86}$.

Para Pere Sánchez Ferré, no hubo ningún motivo político en la disolución y todo se enmarca en cuestiones internas de la Orden ${ }^{87}$. Nosotros creemos que hay suficientes indicios para poder reseñar el carácter político de la operación.

\section{EI declive de la masonería madrileña}

A finales de 1932, se plantea en el Gran Consejo la necesidad de que los diputados masones, estuvieran unidos y conseguir salvar el proyecto de ley sobre Confesiones y Congregaciones religiosas, sobre todo en los postulados de la Orden. El promotor fue

\footnotetext{
${ }^{84}$ En la Unión, estaban además otros amigos de Lerroux, como Dámaso Vélez, Alfonso Reyes, Mateo Congosto, Rafael Gerona, Mariano Benlliure, Joaquín Dicenta, Carlos Malarriaga, Martínez Abad, José Luis Mayral y José Ferrer Sama. Gómez Molleda, La masonería en la crisis española, 434-435.

${ }^{85}$ El Gran Maestre Iniesta de la GLRC se dirige a la logia Constancia 16 de Zaragoza en la que se indica que han sido irradiados Juan Sarradell, Pedro González Blanco, Joaquín Dicenta, Mateo Congosto, Rafael Gerona, Dámaso Vélez; dados de bajo de la Orden sin plancha de quite: Carlos Malariaga, Ernesto Martínez Abad, Alfonso Reyes Antonio de la Osa, José Luis Nairal, José Mañino, Ramón Pérez Día, Mariano Benlliure, Luis Rodríguez Guerra, Juan P. Espinosa, Esteban Vélez, Francisco Ferrari, Antonio Huertas, Alejandro Liebernan, Edmundo Sandig, Rafael Terol, Alfonso Moreno, Teofilo Moreno, Máximo Levi, Manuel Delgado, Alfonso Reyes Senen, José Ferré, Pedro Vélez, Antonio Lagunes, Ricardo Jiménez y José Fernández Murias. Sección Masonería. CDMH, sección Masonería, legajo 4A/7. Expediente de Mariano Benlliure Tuero.

${ }^{86} \mathrm{Su}$ Venerable Maestro siguió siendo Juan Sarradell; el primer Vigilante, Ramón Pérez Díaz; el orador, Pedro González Blanco. Además sabemos que en 1934, seguía habiendo un nutrido número de miembros del partido radical como Lerroux, Abad Conde, M. Cámara Cendoya, Pedro Rico López y José Riquelme López. Siguió publicando la revista Latomía. Gómez Molleda, La masonería en la crisis española, 437-441.

${ }^{87}$ Pere Sánchez Ferré, "La revista Latomía y la logia La Unión de Madrid", en: La masonería en Madrid y España del siglo XVIII al XXI, coord. Ferrer Benimeli (Zaragoza: CEHME, Zaragoza, 2004), Tomo I, 117-120.
} 
Ceferino González ${ }^{88}$. La falta de asistencia de miembros del Consejo, retrasó la toma de decisión que fue postergada hasta el día 18 de febrero de 1933.

Los sucesos de Casas Viejas, en enero de 1933, y el dictamen sobre la "Ley de Confesiones Religiosas" enturbiaron aún más las relaciones del gobierno con los radicales. Por su parte, los socialistas se sentían incómodos en el gobierno, lo que incluso llegó a que estuvieran a punto de abandonarlo en marzo ${ }^{89}$.

El 1 de febrero de 1933, el Gran Maestre de la GLRC, Juan Manuel Iniesta, planteó la necesidad de creación de una liga laica, lo que dio lugar, a la Liga de Educación y Enseñanza (LEYE), que vino a ser la sucesora de la Liga Nacional Laica ${ }^{90}$. Para darle forma se reunieron representantes de logias madrileñas, Génesis, Concordia, Primero de Mayo, Nomos, Hispanoamericana, Matritense, Condorcet, Ibérica y Unión que fue reconstituida tras los sucesos que ya hemos visto, y la huida de muchos miembros a la GLE ${ }^{91}$. Además, y más adelante, se incorporaron la logia de adopción, Reivindicación, y las de reciente creación, Augusto Barcia y Luis Simarro ${ }^{92}$.

El periodo electoral a Gran Maestre del GOE terminó el 15 de junio de $1933^{93}$. El ascenso de la GLRC, y el requisito de que el Gran Maestre tuviera que residir en Madrid parecía que hacia viable la maniobra de Iniesta de aparcar a Martínez Barrio de la dirección del GOE e imponer la política desde las logias madrileñas. Pero los resultados no fueron los esperados, puesto que Don Diego, volvió a ser elegido ${ }^{94}$. Reelección que produjo la salida de los madrileños del Gran Consejo ${ }^{95}$. Pero su maestría fue corta pues duró de junio de 1933 a mayo de 1934.

Las elecciones generales de España que se celebraron a finales de 1933, hicieron perder a la masonería dos tercios de los escaños además de llevar al gobierno, a una alianza de la CEDA con los radicales ${ }^{96}$. Alianza que terminó de envenenar la vida interna de la Orden ${ }^{97}$, especialmente en el caso de la masonería madrileña pues no entendía que se gobernara con

\footnotetext{
${ }^{88}$ Actas del Gran Consejo Federal Simbólico, 8 de diciembre de 1932, 12 en Gómez Molleda, La masonería en la crisis española, 463.

${ }^{89}$ Gómez Molleda, La masonería en la crisis española, 461.

${ }^{90}$ Martín, Los arquitectos de la República, 143.

${ }^{91}$ Coexistiendo la Unión $n^{\circ} 9$ dependiente del GOE y la Unión $n^{\circ} 88$ dependiente de la GLE.

${ }^{92}$ Los fundadores fueron Cámara, Genaro González, Antonio Papell, Inciarte, Manuel Torres Oliveros, Federico Pascual, Aniano Montequi, Zapta, José María Artaiz, Roberto Escribano, Juan Sánchez Pozo, Juan Manuel Herrera, Joaquín Noguera López, Daniel de la Pedraja, Julio Hernández Ibáñez (Pertenecía al Capítulo Esperanza en 1934, año en que era grado 9. Boletín Oficial del Supremo Consejo de Grado 33 para España y sus Dependencias, $n^{\circ}$ 410. Año XLII. Diciembre de 1934), y Simón García Zurdo, Ana María Ronda y Juana García del Pozo. Con posterioridad se unen: Carlos Díaz, Vicente Sos, Rafael Manrique de Lara, Alejandro Redondo, León Laramen, Crédulo Escobar, Elijo de Mateo y Sousa y José Nouvilas. Libro de Actas de la Liga de Educación y Enseñanza, 1 de febrero de 1933 a 22 de junio de 1933 en Gómez Molleda, La masonería en la crisis española, 475.

${ }^{93}$ BOE, 10 de abril de 1933.

${ }^{94}$ Actas del GCFS, 9 y 15 de diciembre de 1932 y Actas del GCFS, 20 de junio 1933, CDHM, sSección Masonería, legajo 686A.

${ }^{95}$ Martín, Los arquitectos de la República, 142-147.

${ }^{96}$ Martínez Barrio, intentó convencer a Lerroux de no aliarse con "la extrema derecha", sin conseguirlo. Diego Martínez Barrio, Memorias. La Segunda República española vista por uno de sus principales protagonistas (Barcelona: Planeta, 1983), 16.

${ }^{97}$ Martín, Los arquitectos de la República, 149.
} 
una organización que estaba dispuesta a acabar con todas las reformas conseguidas y que les había acusado de antipatriotas y fanáticos ${ }^{98}$.

Los críticos volvieron a iniciar una campaña para derrocar al Gran Maestre y a todos los radicales del Consejo ${ }^{99}$ con la excusa de que la masonería era vista por las fuerzas de izquierda como una organización política controlada por los radicales ${ }^{100}$. En la Asamblea de la GLRC de ese año, Iniesta acusó a los masones de haber dado el gobierno a la derecha y de "prostituir sus mandiles". Pero además, creyó necesario "excluir a los malos masones y a los masones intermitentes por decorativos que sean", y exigir a todos "una conducta profana adecuada a la conducta masónica puesto que "la Orden no podía ser por principio estribo para la revolución", pero tampoco "hacer de la Masonería un valladar contra la revolución". En definitiva, la Orden no podía ser "ajena a la lucha contra un estado social injusto"101.

Para estudiar la situación se crea la comisión "de los Nueve"102, lo que provoca la queja de los críticos, por considerarla inoperante y controlada por los radicales. La logia Primero de Mayo, presentó recurso al Gran Maestre con fecha de 29 de marzo de 1934, lamentándose de que en la Comisión no estuvieran representados los afiliados militantes socialistas. En este comunicado, su Venerable, José Eduardo Calver Beltrán, simbólico Yumuti, se quejaba no solo de que no estuviera representado el partido socialista, sino que lo estaba mayoritariamente, el partido radical ${ }^{103}$. Unos días antes, había dimitido Martínez Barrio como ministro de Gobernación del gobierno de Lerroux y el 16 de mayo de 1934, se hizo pública su ruptura con el partido radical ${ }^{104}$.

El 23 de mayo de 1934, se inicia la Asamblea del Gran Consejo, presidido por su vicepresidente, Fermín Zayas. Asisten casi todos los representantes de las Grandes Logias Regionales; y entre ellos, por la GLRC, su Gran Maestre Iniesta, Ceferino González, Roberto Ruiz, Gómez Redondo y Morales; y dos miembros de logias madrileñas representando a las logias de Canarias que se acababan de incorporar al Grande Oriente Español, Aselo Plaza y Eugenio Arauz. El 26 de mayo, Martínez Barrio presenta su dimisión, alegando que "no se debían de tener cargos cuando por deberes ineludibles de orden profano no se podían consagrar al servicio de la Orden el esfuerzo y el tiempo necesario". De manera interina fue nombrado Gran Maestre a Fermín Zayas; Enrique Barea Pérez, pasó a ser Gran Maestre Adjunto. En septiembre, se constituye Unión Republicana, en donde Martínez Barrio,

\footnotetext{
${ }^{98}$ BOGOE año VII, no, 76, (noviembre de 1933), 1.

${ }^{99}$ Martín, Los arquitectos de la República, 149.

${ }^{100}$ Cosa que era cierta, pues incluso Amaro del Rosal planteó la incompatibilidad de ser dirigente del PSOE y miembro de la masonería. La situación hizo que los socialistas, Juan Simeón Vidarte, Fernando de los Ríos y Enrique de Francisco declararan que pedirían su plancha de quite para seguir en la ejecutiva socialista. Vidarte, El Bienio Negro y la insurrección de Asturias. Testimonio del que fue Vicepresidente y secretario del PSOE (Barcelona: Grijalbo, 1978), 141-145.

${ }^{101}$ Discurso de contestación al mensaje del Gran Maestre Regional, en la Asamblea Anual de la Centro. El presidente de la comisión del Mensaje era Antonio Cabrera Tova, diputado en las Cortes por Ciudad Real en Gómez Molleda, La masonería en la crisis española, 494-495.

${ }^{102} \mathrm{Su}$ nombre proviene de que estaba compuesta por nueve maestros: tres designados por Asamblea, tres por la Logia Regional Centro y tres por el Consejo Federal Simbólico y fue convocada tras la Asamblea del GLRC de 19 de noviembre 1933. CDMH. Sección Masonería, 736A/28.

${ }^{103} \mathrm{CDMH}$, sección Masonería, legajo 736A/28.

${ }^{104}$ Martínez Barrio, Memorias, 219.
} 
coincide con algunos de los críticos, como Aselo Plaza y el día 25 de ese mes, el Supremo Consejo del Grado 33 para España y sus Dependencias recuerda a todos los organismos "el deber ineludible [...] de no permitir, [...] tratar en los Templos ningún tema que directa ni indirectamente se relacione con la política partidista" ${ }^{\text {105. }}$.

La crisis política que se está viviendo, complica la vida de la masonería madrileña. Ante esto, las siempre irreconciliables GLE y GOE, hacen un frente común e incluso se puede ver, como algunas logias de ambas obediencias comparten un local en la calle de Alcalá ${ }^{106}$. Ese año, la GLE trasladó su sede a Madrid, siendo Gran Maestre Mariano Larrañaga ${ }^{107}$; desde ese momento los madrileños dirigen la Obediencia hasta la guerra ${ }^{108}$. El 62 por 100 del nuevo consejo de Gobierno de la Obediencia eran masones madrileños, de los cuales el sector más duro, estaba afiliado a la Unión ${ }^{109}$. En julio, el Gran Maestre, Larrañaga, y el Gran Secretario, Sarradell, dimiten siendo sustituidos por Luis Rodríguez Guerra como Gran Maestre y Álvaro Guzmán como Gran Secretario ${ }^{110}$.

\section{De la insurrección de octubre de 1934 al inicio de la guerra de España 1936}

A partir de octubre, las logias de ambas obediencias paran su actividad debido a los acontecimientos represivos que siguieron a la Insurrección ${ }^{111}$. El Gran Consejo del GOE, prohíbe la apertura de trabajos de forma temporal para evitar que los templos "se viesen comprometidos por los sucesos"112. La GLRC se muestra perpleja, pero no los reanuda hasta enero de 1935, pues es desaconsejado por la autoridad gubernamental ${ }^{113}$.

La Asamblea Extraordinaria del GOE de marzo de 1935 en Barcelona, elige a Augusto Barcia, como Gran Maestre ${ }^{114}$, pero ante su dimisión, se convocan elecciones, siendo elegido Ángel Rizo ${ }^{115}$ que toma posesión oficial, el 28 de diciembre de $1935^{116}$.

La Gran Comisión Permanente encarga redactar un anteproyecto de nuevos Estatutos y Reglamentos, a una comisión de la GLRC ${ }^{117}$, con el objeto de modernizar y democratizar

\footnotetext{
${ }^{105}$ Gómez Molleda, La masonería en la crisis española, 504-509 y Boletín Oficial del Supremo Consejo de Grado 33 para España y sus Dependencias, no. 409. Año XLII. (Septiembre de 1934), 4.

${ }^{106}$ Martín, Los arquitectos de la República, 177.

${ }^{107}$ El nuevo Maestre y el nuevo consejo del GLE fue elegido en la Gran Asamblea celebrada en Barcelona en 1933.

${ }^{108}$ Sánchez Ferré, "De la Gran Logia Simbólica Regional Catalana a la Gran Logia Española. Un ejemplo de vocación política", en: Masonería, revolución y reacción, coord. Ferrer Benimeli (Zaragoza: CEHME, 1990), Tomo II, 711.

${ }^{109}$ Martín, Los arquitectos de la República, 173-174.

${ }^{110}$ Boletín Secreto de 5 septiembre de 1934 pp. 1-4 y 9-10 en Martín, Los arquitectos de la República, 108.

${ }^{111}$ Martín, Los arquitectos de la República, 20.

112 Sánchez Ferré, "De la Gran Logia Simbólica Regional Catalana a la Gran Logia Española", 711.

${ }^{113} \mathrm{CDMH}$, sección Masonería, legajo 628A.

${ }^{114} \mathrm{CDMH}$, sección Masonería, legajo 687A.

115 Ángel Rizo, había apoyado a Martínez Barrio, correligionario político, pero a la vez, había mantenido excelentes relaciones con el sector crítico y especialmente con Aselo Plaza, Juan Manuel Iniesta, y Ceferino González Castroverde. En enero de 1936, abandona la logia Tolstoi de Cartagena y se afilia a la logia Luis Simarro $n^{\circ}$ 3, de Madrid. José Antonio Ayala, "Política y Masonería en la II República: Ángel Rizo Bayona, Gran Maestre del G.O.E”, en: Masonería, politica y sociedad, coord. Ferrer Benimeli (Salamanca: CEHME, 1989), Tomo I, 114-118.

${ }^{116}$ CDMH, sección Masonería, legajo 628A y Acta del Gran Consejo de 7 de agosto de 1935.
} 
los altos organismos de la Obediencia. Algunos sectores, consideran que la comisión pretendía politizar la Orden, ya que entre otras medidas, se propone suprimir "la prohibición existente de discutir de política y religión de las logias"118. Agrava aún más la situación que Rizo, el 30 octubre de 1935, emite "una circular [...] para que se depurasen los talleres de la Orden de elementos que hubiesen colaborado con partidos que fuesen enemigos o detractores declarados de la misma". Ofensiva que parecía ir dirigida a los radicales, aliados de la CEDA $^{119}$. Ángel Rizo, no oculta sus deseos de renovar el GOE y apoyar al Frente Popular pero a la vez, defiende volver al apoliticismo ${ }^{120}$.

Por su parte, la GLE, en junio de 1935, elije como Gran Maestre a Juan Sarradell ${ }^{121}$ y en enero de 1936, envía una circular a sus logias pidiendo el apoyo al Frente Popular ${ }^{122}$.

\section{El alzamiento y el inicio de la guerra de España de 1936}

Tras el fracasado golpe de estado de 1936 y el inicio de la guerra, la Orden olvida sus incertidumbres y se posiciona con el frente republicano ${ }^{123}$, consciente de que está en juego los ideales masónicos ${ }^{124}$. A la vez, se hace complicado abrir trabajo en las logias por la falta de miembros, puesto que algunos han huido temiendo la toma de Madrid por los rebeldes; otros se han alistado en el ejército; o pronto seguirán al gobierno y a los Altos Órganos a Valencia $^{125}$, como atestigua la carta del Gran Maestre a la Comisión Ejecutiva de la GLRC informándole que con la autorización de la Gran Logia Regional del Levante, se habían creado tres logias provisionales o circunstanciales en Valencia, dependientes de la GLRC, y "os sugerimos la idea de que aquellos hermanos residentes aun en Madrid cuyas logias no puedan funcionar por falta de números pudieran ser agrupados en logias también provisionales, con lo cual se haría eficaz el trabajo de todos"126. No tenemos constancia de

\footnotetext{
${ }^{117}$ Comisión formada por Juan Manuel Iniesta, Ramón Cuesta, Juan Tébar, Antonio Cabrera y Luis Fernández.

${ }^{118}$ Ayala, "Política y Masonería en la II República", 247-268.

119 Ayala, "Política y Masonería en la II República", 115.

${ }^{120}$ Pedro Fernández Fernández, "Masonería y política”, en: Cuad. Invest. Hist. Brocar 17 (1991): 102.

${ }^{121}$ Martín, Los arquitectos de la República, 179.

${ }^{122} \mathrm{CDMH}$, sección Masonería, legajo 341A/2.

${ }^{123} \mathrm{CDMH}$, sección Masonería, legajo 223A/1.

${ }^{124}$ Gran Consejo Federal Simbólico del GOE, 11 de julio de 1938. CHMH. Sección Masonería, 223A/12

${ }^{125}$ El Gran Consejo siguió al Gobierno Republicano en sus desplazamientos durante la guerra, primero a Valencia, el 6 noviembre de 1936; y un año más tarde, a Barcelona, el 30 de noviembre de 1937. En Valencia se establecieron tres logias circunstanciales que formaron el Primer Grupo y trabajaron del 15 de enero al 29 de octubre de 1937. Por ejemplo, la Accidental $\mathrm{n}^{\circ} 1$ estaba integrada principalmente por miembros de la Condorcet de Madrid. El 9 de diciembre de 1937, la logia Accidental n 1 seguirá trabajando en Barcelona hasta el 15 de mayo de 1938 y el 5 de julio de 1938 acuerda "abatir columnas", reiniciándolos en una logia regular en Barcelona, bajo los auspicios de la GLRC y con consentimiento de la Gran Logia del Nordeste. Para una información completa de estas logias ver Vicent Sampedro Ramo, La maçoneria valenciana i les lògies accidentals durant la Guerra Civil (Valencia: Generalitat Valenciana, 1997) y CDMH. Sección Masonería $359 \mathrm{~A} / 1$.

${ }^{126} \mathrm{CDMH}$, sección Masonería, legajo 736A/24.
} 
que se creara ninguna logia provisional en la capital aunque sí, triángulos y logias en el frente dependientes de la GLRC como el triángulo la "Estrella Roja"127.

El 27 de julio de 1936, Juan Manuel Iniesta, Gran Secretario de la GLRC firma una circular defendiendo el posicionamiento al margen de la política y la religión de la masonería, pero afirmando que sus miembros pueden pertenecer en su vida profana a cualquier partido que defienda la libertad. Resalta que España está siendo amenazada, y que los masones deben empeñar todos sus esfuerzos en defenderla ${ }^{128}$.

Ristori de la Cuadra, Gran Secretario firma otra misiva, el 26 de diciembre de 1936 afirmando que "los francmasones militamos en los partidos de izquierda única y exclusivamente y, por tanto, la lucha actual nos encuentra de lleno y totalmente en el Frente Popular". Algunos elementos de la masonería madrileña como González Castroverde, Gran Maestre adjunto viaja a Francia y Bélgica en 1937, como enviado del Gran Consejo para recabar ayuda económica para el Frente Popular y Juan Manuel Iniesta de la GLRC está en contacto con la Gran Logia de Habla Española en Nueva York y fue a Buenos Aires para recaudar fondos. En agosto de 1937, el Gran Maestre de la AMI, solicita "apoyo moral y financiero para la España antifascista" ${ }^{29}$.

En Madrid, la masonería fue respetada, lo que le permitió en muchos casos proteger a ciudadanos que eran considerados "enemigos" o cercanos al bando sublevado y en ese momento en muchos casos, escondidos en Madrid por miedo a las represalias. Es el caso del masón Rafael Gerona Martínez, que tras la salida de la delegación del Perú de la capital, y aprovechando la amistad con Antonio Ibáñez Gutiérrez, cónsul honorario de ese país, constituye al amparo de esta bandera, un asilo, en el que llegaron a estar acogidas 400 personas $^{130}$.

Para montar el refugio, Gerona consiguió la aprobación del ministro Álvarez Vayo y el apoyo del embajador de Chile, y el decano del cuerpo Diplomático el señor Núñez. Ya nombrado secretario General de la Legación del Perú ${ }^{131}$, alquila unos pisos en la calle Príncipe de Vergara 36 y 38, donde instala a los refugiados. Su funcionamiento, según declaran varios de los residentes, se realizaba por pisos, siendo ellos mismos, los administradores de los fondos. Los súbditos peruanos ${ }^{132}$ y los que no tenían medios, eran mantenidos por el resto. Este asilo, en palabras de Gerona, era una "brigada de Socorro" en la que además de proteger a los residentes, extendían "carnets y avales masónicos a las personas de derechas cuyas vidas peligraban"133.

\footnotetext{
${ }^{127}$ El triángulo se funda el 12 de enero de 1937, perteneciente a los Valles del Ejercito del Pueblo, jurisdicción de la 25 Brigada Mixta y dependiente de la GLRC. Su presidente era Julio Dueso, simbólico Aurrera, de la logia Hispano-Americana. CDMH, sección Masonería, legajo 736A/24.

${ }^{128}$ Sampedro Ramo, La maçoneria valenciana, 75-76.

${ }^{129}$ Ayala, "Política y Masonería en la II República", 119.

${ }^{130}$ Todo lo referente al asilo bajo bandera del Perú, está documentado en el juicio sumarísimo que se emprendió contra Rafael Gerona. AHM fondo Madrid. Sumario 55022 legajo 3833.

${ }^{131}$ En el consejo de guerra también se señala que era Secretario General de la Legación de los EE.UU. de Venezuela. AHM, fondo Madrid, Sumario 55022 legajo 3833.

${ }^{132} \mathrm{El}$ asilo se montó con la excusa de proteger a los súbditos peruanos y con la condición que el resto de los residentes pagasen sus gastos.

${ }^{133}$ Además de Gerona, consta que le ayudaba Peláez y otro masón madrileño, González Blanco.
} 
Gerona, dedicó mucho esfuerzo en recorrer las cárceles, checas, etc., para hacer gestiones y llevar al mayor número posible de personas a las legaciones que funcionaban en Madrid como la de Finlandia, Bolivia, Venezuela o por supuesto, el Perú. Entre los residentes se encontraban nobles, falangistas, religiosos, miembros de partidos de derechas, en definitiva, todos los que corrían peligro.

El refugio estuvo en funcionamiento hasta el 5 de mayo de 1937, en que lo toma la policía y fuerzas de asalto al mando del director de Seguridad Wenceslao Carrillo, pensando que desde allí, se transmitía información a las tropas sublevadas ${ }^{134}$. Hecho que se demostró que no era cierto. Tras esto, los acogidos sufrieron diferente suerte, aunque ninguno fue asesinado ${ }^{135}$. Gerona, a través de Francia se pasó a la "España Nacional" en 1937.

En 1939, a Gerona se le instruye un consejo de guerra, en el que declararon a su favor multitud de personas, entre ellos, muchos de los residentes en el Asilo del Perú, lo que no le valió la clemencia de los vencedores que por el sólo hecho de ser masón, le condenaron a veinte años de cárcel, ingresando en la prisión provincial de Madrid. La solidaridad de Gerona continuó en la posguerra, lo que le costó ser acusado de falso testimonio, al declarar que sabía que Miguel Cámara Cendoya, había abandonado la masonería en 1929, por falta de asistencia y pago, cosa que no era cierta ${ }^{136}$.

Muchos masones madrileños escondieron en sus casas a personas que corrían peligro en los primeros días del Alzamiento, es el caso de Miguel Aranda Guijarro ${ }^{137}$ y Enrique Balenchana Paternay. La solidaridad fue independientemente de la ideología política y religiosa del masón ${ }^{138}$.

En 1938, Desde la logia Accidental de Barcelona parte una moción de censura al Gran Maestre Ángel Rizo. Le acusan de inmoralidad y estafa. La dimisión forzada de Rizo, en mayo de 1938, llevó a la Gran Maestría de forma interina al socialista, Lucio Martínez Gil, último Gran Maestre del GOE en tierras de España y obligado por las circunstancias a salir al exilio $^{139}$.

Mientras, en la zona controlada por los sublevados, fueron fusilados muchos miembros de la masonería, entre ellos, de logias madrileñas como el gobernador civil de Palencia, Enrique Martínez Ruiz Delgado ${ }^{140}$.

\footnotetext{
${ }^{134}$ Claridad, 7 de mayo de 1937; Castilla Libre, 9 de mayo de 1937; El Socialista, 15 de mayo de 1937.

${ }^{135}$ Unos quedaron en libertad, y otros acabaron detenidos en diferentes lugares, como la Checa de Atocha o la cárcel de San Antón. Entre los detenidos estaban los 18 jóvenes que fueron acusados de traición y que tras el juicio fueron declarados inocentes, gracias a las declaraciones de Ibáñez y Gerona.

${ }^{136}$ AHM fondo Madrid. Sumario 55022 legajo 3833.

${ }^{137}$ Simbólico Wagner. Pertenecía a la logia Génesis. Era de Izquierda Republicana. Médico. Protegió a muchas personas, entre ellas varias religiosas en su propio domicilio. Se le absuelve de los delitos de rebelión pero se envía su expediente al Tribunal de Represión de la Masonería. AHM, fondo Madrid Sumario 9738 caja 1652/5.

138 Simbólico Cal. Perteneció a la logia Solidaridad y Mare Nostrum 11. Grado $3^{\circ}$. Ingeniero Agrónomo. Miembro de Acción Republicana, del partido Socialista y de la UGT. Protegió a muchas personas, entre ellas, a varias religiosas que tuvo en su casa. Al final de la guerra ingresó en la prisión de Polier. Condenado a 20 años de reclusión, siéndole rebajada la pena a 6 años. AHM, fondo Madrid. Sumario 8703. Caja 365/1.

139 Ayala, "Política y Masonería en la II República", 120-121.

${ }^{140}$ Carta del Supremo Consejo de Grado 33 de España al Supremo Consejo de Grado 33 de Inglaterra de 24 de abril de 1937, en el que se le informa de los fusilamientos de masones en zona sublevada. CDMH, sección Masonería, legajo 789A.
} 


\section{La represión de los masones madrileños en la posguerra}

Con el fin de la Guerra, y la toma de Madrid, se inicia un periodo de búsqueda y detención de los masones madrileños que no habían podido huir o se habían quedado esperando no tener problemas con el nuevo régimen. Se establecen juicios sumarísimos, consejos de guerra, etc., lo que lleva a que sufran multas, incautación de bienes, purgas, depuración, cárcel o la pena de muerte ${ }^{141}$.

Como ejemplo, de masones madrileños que se quedaron y fueron detenidos, juzgados y acusados de rebelión y/o pertenencia a la masonería tenemos a Miguel Cámara Cendoya ${ }^{142}$, Francisco Escola Besada ${ }^{143}$, Rafael Gerona Martínez, Antonio Alcázar García ${ }^{144}$, Miguel Aranda Guijarro ${ }^{145}$, Enrique Balenchana Paternay, Julian Cervantes Infantes ${ }^{146}$, Joaquín Dicenta Alonso $^{147}$, etc. Algunos, los menos, fueron solo condenados a inhabilitación perpetua a cargo público, es el caso por ejemplo, de Cipriano Bernal de Pulga ${ }^{148}$, Pedro Cifuente Díaz $^{149}$; o excepcionalmente, puestos en libertad como Francisco Escola Besada ${ }^{150}$.

\footnotetext{
141 Para una información más completa sobre la represión de los masones ver Juan José Morales Ruiz, "Represión de los masones en la guerra civil española", en: Revista de Francmasonería CM Cultura Masónica 19 (2014): 67-105 y Yván Pozuelo Andrés, "La II República Española (1931-1939). A contracorriente”, en: Revista de Francmasonería CM Cultura Masónica 19 (2014): 21-27

${ }^{142}$ Simbólico Teide. Grado 3. Se inició el 3 de mayo de 1921, en la logia Cantoniana. Miembro de las logias Cantoniana 336, Unión 9. Fue fundador de la logia Unión. La logia Paz, Trabajo y Justicia 7 de Cartagena. Nació el 21 de enero de 1893, en Santander. Periodista y abogado. Miembro del partido Radical, concejal de Madrid, diputado a Cortes por Alicante, secretario Político del Ministro de la Gobernación, subsecretario de la Presidencia y director Comercial de la Telefónica. Le acusan de proteger candidaturas de derechas. Condenado a 4 años, 11 meses y 29 días por tribunales populares. Tras la guerra, es condenado a 20 años de reclusión menor e inhabilitación absoluta perpetua. CDMH, sección Masonería, legajo 40B/6.

${ }^{143}$ Simbólico Salvochea. Iniciado en 1907 en la logia Progreso. Fundador de la logia Condorcet. Grado 18. Logias Progreso, Ibérica 7, Condorcet, Unión 9, Hispanoamericana 379. Nació el 25 de julio de 1884. Periodista. Perteneció a las Juventudes Republicanas en Cádiz, a la Unión Republicana de Nicolás Salmerón e Izquierda Republicana. Fue gobernador Civil de Castellón y durante la guerra estuvo en el gabinete de Censura de Prensa y en el ministerio de la Gobernación. Se le condena a 25 años de reclusión mayor y accesoria. CDMH, sección Masonería, legajo 139A/24.

${ }^{144}$ Estuvo en el frente en el ejército republicano. Condenado a 6 años y un día de prisión mayor por "Auxilio a la Rebelión". AHM, fondo Madrid, Sumario 45953 caja 77 nº 11.

${ }^{145}$ Se le absuelve de los delitos de rebelión pero se remite su expediente por ser masón al Tribunal Especial de Represión de la Masonería el 25 de junio de 1941. AHM, fondo Madrid, 9738 caja 1652/5

${ }^{146}$ Se le condena por capitán del ejército rojo. Fue administrador del Hospital de Sangre de Villena. Era de Izquierda Republicana, Unión Republicana y del sindicato CNT. Condenado a 1 año de prisión. No aparece en el Sumario su pertenencia a la masonería. AHM, fondo Alicante, Sumario 7178. Caja 15457/8. Pertenecía a la Ibérica, iniciado el 1/1/1926. Nombre simbólico Casero. Salmón Moviola, Los masones de Madrid (1939). Repertorio de miembros, acción cultural y comunicación social (La Laguna: Editorial Relax Color (CD), 2006). ${ }^{147}$ AHM, fondo Madrid, Sumario 13149, legajo 4595.

${ }^{148}$ Simbólico Lavoisier. Nació el 1 noviembre de 1867 . Se inició en 1884 o 1885 . Grado $4^{\circ}$. Perteneció a las logias Comuneros de Castilla, Unión 9, Esperanza. Fue fundador junto a Juan Sarradell del triángulo la Unión. Se pide 12 años y un día de reclusión menor, pero por no haberse demostrado continuidad en la secta, su avanzada edad, su estado físico y su escasa peligrosidad se le aplica la inhabilitación absoluta. CDMH, sección Masonería, legajo 756B/3.

${ }^{149}$ Simbólico Miguel Servet, grado 3, miembro de la Unión no 9 en 1932 y 1934. Académico numerario de la Real Academia de medicina. Se pasó a la zona sublevada en 1937 y se afilió a la FET y de la JONS, capitán médico del bando sublevado el 13 de julio de 1939. Condenado a inhabilitación perpetua, CDMH, sección Masonería, legajo 711B/11.

${ }^{150}$ AHM, fondo Madrid, Sumario 139728 legajo 7547.
} 
La mayoría de los que pudieron salir, antes de la caída de Madrid, lo hicieron desde Barcelona hacia Francia en los primeros meses de 1939, y desde ahí, los que tuvieron más suerte embarcaron a América, es el caso de Mariano Benlliure ${ }^{151}$, Crescenciano Aguado Merino $^{152}$, Cándido Bolivar y Pieltain ${ }^{153}$, Catalina Burgos Seguí ${ }^{154}$, Manuel Torres Campaña ${ }^{155}$, Segismundo Casado López ${ }^{156}$ Herminio Álvarez García, Juan Pablo Álvarez García, Eugenio Arauz Pallardo, José Berenguer Cros, Juan Botella Asensi, Francisco Carreras Reura, Roberto Castrovido Sanz, Fernando de los Ríos, Cándido Bolívar Pieltain, Demófilo de Buen, Enrique Barea, Iniesta, etc.

Otros no tuvieron tanta suerte, y fueron fusilados, es el caso de Eduardo Barriobero Herrán, el 10 de febrero de 1939 en Barcelona o Eleuterio Díaz-Tendero Merchán ${ }^{157}$, que acabó en el campo de concentración de Dachau después de que las tropas alemanas ocupasen Francia y muerto en el mismo, el 13 de febrero de 1945.

También hubo masones madrileños en el bando sublevado. Es el caso de Miguel Cabanellas Ferrer, general de división y jefe de la Quinta División Orgánica en Zaragoza, uno de los jefes golpistas de mayor rango. Entre el 24 de julio al 30 de septiembre de 1936, fue el jefe de la Junta de Defensa Nacional de Burgos ${ }^{158}$ o que murieron víctimas de milicias republicanas es el caso de Gerardo Abad Conde ${ }^{159}$.

\section{Conclusiones}

Es difícil decidir si los masones madrileños entraron en política para llevar sus principios al mundo profano o si fueron los políticos los que entraron en la masonería para

\footnotetext{
${ }^{151}$ Simbólico Padilla, nació el 31 de octubre de 1888, escritor y periodista e hijo del escultor Mariano Benlliure y Gil. Se inició en Dantón, el 24 de noviembre de 1926, fue miembro de la logias Dantón, Hiram 95, la Unión 9, La Unión 88. Gran Orador de la GLRC, Gran Consejero de la GLE y vicepresidente de la Liga de los Derechos Humanos en 1933, redactor en la Revista Latomía. Condenado a 20 años y un día de reclusión mayor por el Tribunal de Represión de la Masonería. En 1942 residía en París. CDMH, sección Masonería. Legajo 4A/7. Expediente de Mariano Benlliure Tuero.

${ }^{152}$ Simbólico Marx. Nació en Autilla del Pino el 14 de septiembre de 1893 y murió en Madrid en 1979. Registrador de la Propiedad. Socialista. Diputado por Palencia en 1933. Durante la guerra civil fue director general de Rentas Públicas y secretario del Consejo de Dirección del ministerio de Hacienda. Se inició en la masonería en 1931. Perteneció a la logia Condordia 14. Se exilió en México el 13 de junio de 1939. AHM,fondo Madrid, Sumario 42447 legajo 7006.

${ }^{153}$ Exiliado en México. AHM. Fondo Madrid, Sumario 34626 expediente 2780.

${ }^{154}$ Se supone que salió al exilio. AHM. Fondo Madrid, Sumario 31087 legajo 1985.

${ }^{155}$ AHM, fondo Madrid, Sumario 53670 legajo 6531.

${ }^{156}$ AHM, fondo Madrid, Sumario 1346 legajo 602.

${ }^{157}$ Simbólico Eleusis. Logias Matritense 12 y Accidental no 1 de Valencia. BBDD personal, y Sampedro Ramo, La maçoneria valenciana, 167.

${ }^{158}$ Miembro de la Mare Nostrum. BBDD del autor.

159 Simbólico Justicia. Iniciado en la Logia Hispanoamericana 379 en 1919. Grado 33. Perteneció a las logias Hispanoamericana, Suevia ${ }^{\circ} 4$ y de Curros Enríquez de A Coruña, Libredón en Santiago de Compostela, Unión $n^{\circ} 9$, Esperanza $n^{\circ} 8$. Vocal de la Junta reorganizadora de la Liga de Derechos del Hombre. Pidió plancha de quite en 1933. Nació en A Coruña el 8 de agosto de 1881. Perteneció al partido Radical. Concejal de A Coruña, y alcalde en 1918-1919, subsecretario de Comunicaciones en el gobierno Provisional, presidente del patronato para la Incautación de bienes de los jesuitas, ministro de Marina entre enero y abril de 1935. Abogado. Fue detenido en Madrid, ingresó en la cárcel de Porlier, y asesinado el 10 de septiembre de 1936. BBDD del autor.
} 
utilizarla. En nuestra opinión, hubo un poco de ambas cosas, siendo evidente que la masonería madrileña luchó por construir la República en la que creía.

Fue imposible, el intento de muchos de volver al apoliticismo propio de la masonería, que habían perdido en la dictadura de Primo de Rivera, especialmente debido a la posición de los "críticos". Además, muchos de los diputados, miembros del gobierno y de la Administración Pública, que estaban involucrados en la construcción republicana, pertenecían a logias madrileñas, entre otras, a Ibérica, Catoniana, Luis Simarro, Hispanoamericana, Dantón, Mare Nostrum, Concordia o Primero de Mayo es decir, las logias más politizadas.

Tras el inicio de la guerra, se implican aún más en apoyo del Régimen Republicano, pero también en defensa de los perseguidos por los grupos incontrolados que en los primeros meses de la sublevación controlaban las calles de Madrid.

El enfrentamiento, fue visto por los masones madrileños como el de dos formas diferentes de entender el mundo, y al posicionarse mayoritariamente, por uno de los contendientes, el perdedor; les supone recibir una violencia encarnizada. Violencia que les obliga a tomar el camino del exilio, enfrentarse a la cárcel e incluso a la muerte. También encontramos masones en el bando vencedor, lo que en muchos casos no les libró del peso de la ley franquista, por el simple hecho de ser masones.

Por último, indicar que aunque uno de sus principios básicos es que "La masonería no está ni puede afiliarse a ninguna religión positiva ni formar parte de ningún partido político" 160 , consideramos, que a los masones madrileños, les cuesta aunar las dos militancias política-masónica, y por ello, para muchos, como dirá Enrique Barea: "La Masonería es política o no es nada" ${ }^{\text {161 }}$.

\section{Bibliografía}

Alcalá-Zamora, Niceto. Memorias. Barcelona: Planeta, 1998.

Arbeloa, Víctor Manuel. La Semana Trágica de la Iglesia en España: 8-14 de Octubre de 1931. Madrid: Encuentro, 2006.

Azaña, Manuel. Memorias politicas y de guerra. Barcelona: Grijalbo, 1996.

Manuel AZAÑA, Obras Completas. Tomo IV. México: Oasis, 1966.

Avilés Farré, Juan. “Acerca de la Masonería”. En: Revista del libro 119 (2006): 10-11.

Avilés Farré, Juan. La Izquierda Burguesa y la tragedia de la II República. Madrid: Comunidad de Madrid, 2006.

Ayala, José Antonio. "Política y Masonería en la II República: Ángel Rizo Bayona, Gran Maestre del G.O.E”. En: Masonería, politica y sociedad. Coordinado por José Antonio Ferrer Benimeli. Salamanca: CEHME, 1989.

Cruz, José Ignacio. "La masonería española y los debates políticos de la II República”. En: Revista Masónica CM Cultura Masónica 19 (2014): 29-50.

Domingo Sanjuán, Marcelino. La experiencia del poder. Madrid: Javier Morata, 1934.

\footnotetext{
${ }^{160}$ Boletín Oficial del Grande Oriente Español, noviembre de 1933, 23.

${ }^{161}$ Frase que pronunció Enrique Barea Pérez, simbólico Betis, miembro de la logia Hispanoamericana, en la Asamblea de Sevilla de 1925.
} 
Fernández Fernández, Pedro. "Masonería y política”. En: Cuad. Invest. Hist. Brocar 17 (1991): 91-102.

Ferrari Billoch, F. La Masonería al desnudo. Las Logias Desenmascaradas. Madrid: Bergua, 1936.

Gómez Molleda, María Dolores. La masonería en la crisis española del siglo XX. Madrid: Taurus, 1989.

Márquez, F, Poyán, C, Roldán, T y Villegas, M.J. La Masonería en Madrid. Madrid: Avapiés, 1998.

Martín, Luís P. Los arquitectos de la República: Los masones y la política en España, 19001936. Madrid: Marcial Pons, 2007.

Martínez Barrio, Diego. Memorias. La Segunda República española vista por uno de sus principales protagonistas. Barcelona: Planeta, 1983.

Morales Ruiz, Juan José. "Represión de los masones en la guerra civil española". En: Revista de Francmasonería CM Cultura Masónica 19 (2014): 67-105.

Ortiz Albear, Natividad. Las mujeres en la Masonería. Málaga: Atenea. 2005.

Pozuelo Andrés, Yván. "La II República Española (1931-1939). A contracorriente”. En: Revista de Francmasonería CM Cultura Masónica 19 (2014): 21-27.

Pozuelo Andrés, Yván. La masoneria en Asturias (1931-1939). Universidad de Oviedo, 2012.

Roldan Rabadán, María Teresa. "Cuestiones políticas y sociales tratadas por algunas logias madrileñas". En: Symposium de Metodología Aplicada a la Historia de la Masonería Española. Coordinado por José Antonio Ferrer Benimeli. Zaragoza: CEHME, 1987.

Salmón Moviola, Olivia. "La geopolítica de la masonería en Madrid, 1910-1936". En La masonería española en el 2000. Una revisión histórica. Coordinado por José Antonio Ferrer Benimeli. Zaragoza: Gobierno de Aragón, 2001.

Salmón Moviola, Olivia. La palabra de paso. Identidades y transmisión cultural en la masonería de Madrid (1900-1936). Santa Cruz de Tenerife: Idea, 2008.

Salmón Moviola, Olivia. Los masones de Madrid (1939). Repertorio de miembros, acción cultural y comunicación social. La Laguna: Editorial Relax Color (CD), 2006.

Sampedro Ramo, Vicent. La maçoneria valenciana i les lògies accidentals durant la Guerra Civil. Valencia: Generalitat Valenciana, 1997.

Sánchez Ferré, Pere. "La revista Latomía y la logia La Unión de Madrid". En: La masonería en Madrid y España del siglo XVIII al XXI. Coordinado por José Antonio Ferrer Benimeli. Zaragoza: CEHME, 2004.

Sánchez Ferré, Pere. "De la Gran Logia Simbólica Regional Catalana a la Gran Logia Española. Un ejemplo de vocación política”. En: Masonería, revolución y reacción. Coordinado por José Antonio Ferrer Benimeli. Zaragoza: CEHME, 1990.

Villa García, Roberto. "La logia Hispanoamericana no 379 de Madrid (1915-1935)”. En: La masonería en Madrid y en España del siglo XVIII al XXI. Coordinado por José Antonio Ferrer Benimeli. Zaragoza: CEHME, 2004.

Vidarte, Juan Simeón. El Bienio Negro y la insurrección de Asturias. Testimonio del que fue Vicepresidente y secretario del PSOE. Barcelona: Grijalbo, 1978.

Vidarte, Juan Simeón. Las Cortes Constituyentes de 1931-1933. Barcelona: Grijalbo, 1976. 